\title{
Exhaled breath analysis in the diagnosis of head and neck cancer
}

\author{
Mäkitie, Antti A.
}

2020-04

Mäkitie , A A , Almangush , A , Youssef , O , Metsälä , M , Silen , S , Nixon , I J , Haigentz , M , Rodrigo , J P , Saba , N F , Vander Poorten , V \& Ferlito , A 2020 , ' Exhaled breath analysis in the diagnosis of head and neck cancer ', Head \& Neck, vol. 42 , no. 4 , pp. 787-793 . https://doi.org/10.1002/hed.26043

http://hdl.handle.net/10138/323511

https://doi.org/10.1002/hed.26043

acceptedVersion

Downloaded from Helda, University of Helsinki institutional repository.

This is an electronic reprint of the original article.

This reprint may differ from the original in pagination and typographic detail.

Please cite the original version. 
Head and Neck

WILEY

\section{Exhaled Breath Analysis in the Diagnosis of Head and Neck Cancer}

\begin{tabular}{|c|c|}
\hline Journal: & Head \& Neck \\
\hline Manuscript ID & HED-19-1009.R1 \\
\hline Wiley - Manuscript type: & Clinical Review \\
\hline $\begin{array}{r}\text { Date Submitted by the } \\
\text { Author: }\end{array}$ & $\mathrm{n} / \mathrm{a}$ \\
\hline Complete List of Authors: & $\begin{array}{l}\text { Makitie, Antti; Helsinki University Central Hospital, Department of } \\
\text { Otolaryngology; } \\
\text { Almangush, Alhadi; University of Helsinki, } \\
\text { Youssef, Omar ; Helsingin Yliopisto } \\
\text { Metsälä , Markus; University of Helsinki } \\
\text { Silén, Suvi; University of Helsinki } \\
\text { Nixon, Iain; ENT department Edinburgh } \\
\text { Haigentz, Missak; Morristown Medical Center, Medical Oncology } \\
\text { Rodrigo, Juan P.; Hospital Universitario Central de Asturias, Department } \\
\text { of Otolaryngology; Instituto Universitario de Oncología del Principado de } \\
\text { Asturias, } \\
\text { Saba, Nabil; Emory University, winship cancer institute } \\
\text { Vander Poorten, Vincent; KU Leuven, Department of } \\
\text { Otorhinolaryngology; } \\
\text { Ferlito, Alfio; International Head and Neck Scientific Group }\end{array}$ \\
\hline Key Words: & $\begin{array}{l}\text { Head and neck cancer, Exhaled breath analysis, Diagnosis, volatile } \\
\text { organic compounds, Exhaled breath condensate }\end{array}$ \\
\hline
\end{tabular}




\title{
Exhaled Breath Analysis in the Diagnosis of Head and Neck Cancer
}

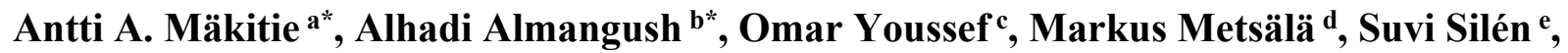 \\ Iain J. Nixon ${ }^{\text {f, Missak Haigentz }}{ }^{\text {, , Juan P. Rodrigo }}{ }^{\text {h, Nabil F. Saba }}{ }^{\text {, }}$, Vincent Vander \\ Poorten $^{j}$, Alfio Ferlito ${ }^{k}$
}

\begin{abstract}
Affiliations
Antti A. Mäkitie MD, PhD (ORCID ID https://orcid.org/0000-0002-0451-2404)

a Department of Otorhinolaryngology - Head and Neck Surgery, University of Helsinki and Helsinki University Hospital, Helsinki, Finland

Research Program in Systems Oncology, Faculty of Medicine, University of Helsinki, Helsinki, Finland

Division of Ear, Nose and Throat Diseases, Department of Clinical Sciences, Intervention and Technology, Karolinska Institutet and Karolinska Hospital, Stockholm, Sweden

E-mail: antti.makitie@,helsinki.fi
\end{abstract}

\author{
Alhadi Almangush DDS, $\mathrm{PhD}$ \\ ${ }^{\mathrm{b}}$ Department of Pathology, University of Helsinki, Helsinki, Finland. \\ Research Program in Systems Oncology, Faculty of Medicine, University of Helsinki, Helsinki, \\ Finland. \\ Institute of Biomedicine, Pathology, University of Turku, Turku, Finland. \\ Faculty of Dentistry, University of Misurata, Misurata, Libya. \\ E-mail: alhadi.almangush@,helsinki.fi \\ Omar Youssef MD, PhD \\ ${ }^{\mathrm{c}}$ Department of Pathology, University of Helsinki, Helsinki, Finland. \\ Research Program in Systems Oncology, Faculty of Medicine, University of Helsinki, Helsinki, \\ Finland. \\ E-mail: omar.youssef@,helsinki.fi
}

Markus Metsälä PhD (ORCID ID https://orcid.org/0000-0002-0716-7132)

${ }^{\mathrm{d}}$ Department of Chemistry, University of Helsinki, P.O. Box 55, FI-00014 Helsinki, Finland E-mail: markus.metsala@,helsinki.fi

Suvi Silén $\mathrm{MD}, \mathrm{PhD}$

e Department of Otorhinolaryngology - Head and Neck Surgery, University of Helsinki and Helsinki University Hospital, Helsinki, Finland

E-mail: suvi.silen@helsinki.fi

Iain J. Nixon MD, MBChB, FRCS (ORL-HNS), PhD

${ }_{\mathrm{f}}^{\mathrm{f}}$ Department of Otolaryngology, Head and Neck Surgery, NHS Lothian, Edinburgh University, Edinburgh, UK

E-mail: iain.nixon@,nhs.net 
Missak Haigentz, Jr. MD

g Department of Hematology/Oncology, Morristown Medical Center/Atlantic Health System E-mail: Missak.Haigentz@atlantichealth.org

Juan P. Rodrigo MD, $\mathrm{PhD}$

${ }^{\mathrm{h}}$ Department of Otolaryngology, Hospital Universitario Central de Asturias-University of Oviedo, ISPA, IUOPA, CIBERONC, Oviedo, Spain

E-mail: jprodrigo@uniovi.es

Nabil F. Saba MD

${ }^{i}$ Department of Hematology and Medical Oncology, Winship Cancer Institute, Emory University, Atlanta, GA, USA

E-mail: nfsaba@emory.edu

Vincent Vander Poorten MD, PhD

j Department of Otorhinolaryngology-Head and Neck Surgery and Department of Oncology, Section of Head and Neck Oncology, University Hospitals Leuven, KU Leuven, Leuven, Belgium E-mail: vincent.vanderpoorten@uzleuven.be

Alfio Ferlito MD, DLO, DPath,FRCSEd ad hominem, FRCS (Eng, Glasg, Ir) ad eundem, FDSRCS ad eundem, FHKCORL, FRCPath,FASCP, IFCAP

${ }^{\mathrm{k}}$ Coordinator of the International Head and Neck Scientific Group, Padua, Italy

E-mail: alfio.ferlito@uniud.it

This article was written by members and invitees of the International Head and Neck Scientific Group (www.IHNSG.com).

Conflict of interest: The authors declare no conflict of interest

\section{Corresponding author:}

Antti A. Mäkitie MD PhD

Department of Otorhinolaryngology - Head and Neck Surgery, Helsinki University Hospital

P.O.Box 263

FI-00029 HUS

Helsinki, Finland

E-mail: antti.makitie@helsinki.fi

Tel.: +358-50-428 6847

*equal contribution. 
Abstract

Head and Neck cancer (HNC) comprises a heterogeneous group of upper aerodigestive tract malignant neoplasms the most frequent of which is squamous cell carcinoma. HNC forms the eighth most common cancer type and the incidence is increasing. However, survival has improved only moderately during the past decades. Currently, early diagnosis remains the mainstay for improving treatment outcomes in this patient population. Unfortunately, screening methods to allow early detection of HNC are not yet established. Therefore, many cases are still diagnosed at advanced stage, compromising outcomes. Exhaled breath analysis (EBA) is a diagnostic tool that has been recently introduced for many cancers. Breath analysis is non-invasive, cost-effective, time saving, and can potentially be applied for cancer screening. Here, we provide a summary of the accumulated evidence on the feasibility of EBA in exhaled breath analysis-the diagnosis of HNC.

Keywords: Head and neck cancer; Exhaled breath analysis; Diagnosis. 


\section{Introduction}

Head and Neck Cancers (HNCs) constitute a heterogenous group of neoplasms. A recent report based on GLOBOCAN database estimated the diagnosis of more than 500000 new cases of HNC during $2018^{1}$, and incidence is expected to continue increasing according to estimates for $2030^{2}$. HNC is associated with high mortality ${ }^{1}$, and one of the main reasons for the low survival can be explained by late stage of diagnosis. As a result, the development of effective early detection strategies is seen as an important approach to improve curative treatment outcomes ${ }^{3,4}$.

Current methods to detect HNCs include visual inspection of the upper aerodigestive mucous membranes and pathological examination of tissue biopsy of suspicious lesions. Serological and salivary biomarkers are under evaluation to aid in the early primary diagnosis or follow-up surveillance of this patient population, but none has yet been proven useful in clinical practice ${ }^{5,6}$. Therefore, more reliable and non-invasive methods are warranted for early diagnosis of HNC. The purpose of this review is to provide a summary of the existing evidence on the feasibility of exhaled breath analysis (EBA) in the diagnosis of HNC.

\section{Exhaled breath analysis}

Non-invasive approaches to the early diagnosis of cancer are crucial topic of research. Available methods include, for example, surface brushing, saliva and blood sampling. The aim of these approaches is to identify cancer biomarkers or signatures that would allow early detection of cancer before any clinical symptoms or signs develop. Such early diagnosis could lead to identification, treatment planning and intervention of the disease at an early stage and that, indeed, could improve clinical outcome ${ }^{7}$. However, routine diagnosis of many cancers (including those of head and neck) is still based on evaluation of changes in macroscopic appearance, radiological features and 
histopathological characteristics. The tools that are used in this traditional evaluation are not easily applicable in population screening as these diagnostic examinations are invasive, expensive, and/or time-consuming, and may involve exposure to radiation.

In contrast, analysis of exhaled breath may represent a non-invasive, rapid and inexpensive screening tool that has shown promising results in many cancers ${ }^{8-14}$. Easy access to sample supply is one of main advantages of breath analysis. The main gas phase constituents of exhaled breath are carbon dioxide, nitrogen, oxygen, water vapor and argon. In addition to these compounds, many volatile organic compounds (VOCs) are present at trace amounts, from part-per-million (ppm, $10^{-6}$ ) to down to part-per-trillion (ppt, 10-12) levels. VOCs can be transferred to blood either in the lungs via gas exchange between alveoli and blood or they can be released in the lower or upper airways (including the oral and nasal cavity) ${ }^{15}$. These volatile species can be analyzed in the gas phase using various mass spectrometry techniques, optical spectroscopy ${ }^{16}$ or sensors based on, for example, nanoparticles or semiconductive metal oxides ${ }^{17}$. In addition to sampling the exhaled gas, breath samples can also be collected by condensing the breath on a cooled surface. The so-called exhaled breath condensate (EBC) is composed mostly of condensed water vapor but will also include small amounts of respiratory droplets containing nonvolatile molecules and water-soluble volatile compounds ${ }^{18}$ as well as bacteria and viruses ${ }^{19}$. The content of the EBC can be analyzed, for example, using enzyme immunoassay kits or chromatography - mass spectrometry techniques. The theory of exhaled breath analysisEBA for cancer diagnosis is based on the concept that cancer initiation is associated with increase in oxidative stress that can cause alteration in the profile of deoxyribonucleic acid (DNA), proteins and other components ${ }^{20}$. Such alterations can be detected in exhaled breath as increased or decreased concentrations of biomarkers connected with a specific disease that is associated with specific pathologic changes 
21,22. The history of research on breath analysis is strongly associated with Linus Pauling, the Nobel Prize winner in 1971, who explained that human breath is a complex gas mixture containing more than 200 VOCs $^{23}$. To date, almost 900 different VOCs have been detected in exhaled breath ${ }^{24}$.

\section{Methodological aspects in exhaled breath analysis}

Collection procedure: The collection procedure for a breath sample depends on whether the aim is to collect the gas phase portion of breath or the EBC. For gas phase samples, breath is either collected to sorbent materials or sample bags (offline analysis) or it can be analyzed immediately after the sample collection (online analysis). Storage in sorbent tubes or bags introduces risks related to sample stability during handling and storage ${ }^{25}$. Exhalations can be divided into three phases. The brief initial phase contains gas from the oral cavity and trachea, this is often called "dead space phase". The next phase is the mixed expiratory phase in which gas from the lungs and lower airways mixes with the dead space sample. The final phase is the end-tidal, which most closely reflects alveolar gas in the lungs. In most applications of breath analysis, the focus is on collecting the end-tidal phase and the first two phases are discarded. This can be done by real-time monitoring of the carbon dioxide content during sampling. Carbon dioxide originates fully from the alveolar gas-exchange and can be used as a marker for the end-tidal phase ${ }^{25}$. However, in the case of HNC, the first two phases should not be discarded as they should contain the most relevant biomarkers for cancers in the upper aerodigestive tract.

Exhaled breath is saturated with water at the temperature of the airways. If the temperature of the breath sample is lowered, condensation occurs. The EBC is normally collected at temperatures below $4{ }^{\circ} \mathrm{C}$. Collecting devices for EBC use several different types of cooling maneuvers such as dry ice, wet ice with salt, and liquid nitrogen, and accordingly the condensate 
can be either liquid, solid or mix of both ${ }^{26,27}$. EBC analysis is always performed offline. Importantly, it has been reported that the condensation temperature could affect different biomarkers' concentration and therefore, reporting the condensation temperature is essential for process standardization and registration ${ }^{27}$. There is a wide variety of commercial EBC collection devices such as EcoScreen Turbo ${ }^{28}$, TURBO-DECCS ${ }^{29}$, RTube ${ }^{\mathrm{TM}}{ }^{30}$, and devices for specific patient groups e.g. infants and children ${ }^{31-33}$, and mechanically ventilated patients ${ }^{34}$.

\section{Duration of sample collection: Duration of sample collection is dependent on the used technique.}

For gas phase sampling, the sampling time can be as short as the duration of a single exhalation (seconds). When collecting the breath on a sorbent material, the concentrations of the analyte gases can be enriched by using longer sampling times (minutes). In bag or online sampling, several samples can be acquired in succession to reduce the inter-individual variation of breath levels. Various physiological factors, such as breath holding, increased tidal volume and hyperventilation can have an influence on the retrieved breath concentrations but no universal breath gas sampling procedure currently exists. Some specific breath tests, which are already in clinical use have been standardized, an example being the fractional nitric oxide (FeNO) test for measuring airway inflammation ${ }^{35}$.

Although the majority of published studies recommend EBC sample collection of 10 to 30 minutes, some studies have reported short collection times of 3 minutes and others prolong the time up to 60 minutes ${ }^{36}$. The approximate volume of exhaled breath condensateEBC after 10 to 15 minutes of breathing is $1-3 \mathrm{ml}^{37}$. Clearly, the length of sample collection time has a direct effect on the final volume ${ }^{36}$. Increased tidal volume and/or minute ventilation, hyperventilation 
and mechanical ventilation are all associated with an increase in the volume of exhaled breath condensateEBC ${ }^{38-40}$.

Sample storage: When using offline gas phase samples, the storage temperature and time depend on whether the sample is stored in a bag or a sorbent material. The optimal temperature for bag storage is $37^{\circ} \mathrm{C}$ to avoid water condensation on bag surfaces. Storage losses depend heavily on the specific biomarkers and the collection bag material. Bags manufactured from Tedlar have been shown to be stable for many compounds for up to 6 hours of storage ${ }^{41}$. For samples collected onto a sorbent tube, a stable storage time of 1.5 months was achieved at $-80{ }^{\circ} \mathrm{C}$. However, of almost 600 compounds that were studied, a significant amount showed discernible levels of change in concentration after six months of storage ${ }^{42}$.

The optimum temperature for an $\mathrm{EBC}$ sample storage is below $-70^{\circ} \mathrm{C}$. However, some biomarkers require assessment of their stability at the storage temperature. Furthermore, division of the exhaled breath samples into aliquots is recommended as repetitive freezing and thawing for analysis may result in breakdown of certain compounds such as nucleic acids and prostaglandins 43. These parameters do vary between the investigated individual markers.

Potential contamination by saliva and oral bacterial activity: Salivary contamination can occur during collection of $\mathrm{EBC}$ and it is an important confounding factor, especially when analyzing volatile biomarkers. A clear example of salivary contamination is that exhaled breath nitrite levels are mostly attributable to oropharyngeal bacterial flora, as their levels decrease drastically following rinsing of the mouth with a chlorhexidine solution ${ }^{44}$. Salivary contamination can be prevented or minimized by using a saliva trap and by placing the exhaled breath condenser at a 
higher level than mouth and thus making it unlikely for saliva to enter the collecting device ${ }^{18}$ : Exclusion of saliva contamination can be done by testing salivary amylase in the EBC sample ${ }^{45,46}$. Additionally, the ATS/ERS Task Force on EBC recommend using a nasal clip to minimize the entry of nasal airway lining fluid into the sampled air and to ensure that all exhaled air will pass through the mouth ${ }^{18}$. Oral bacteria and oral enzymatic activity can also influence the exhaled gas concentrations. For example, exhaled ammonia is mainly produced by enzymatic hydrolysis of urea in the oral cavity ${ }^{47}$. The contribution of the oral cavity to the exhaled gas concentrations can be minimized by the use of an antiseptic ${ }^{48}$.

\section{Potential breath biomarkers of HNC}

In many neoplasms, exhaled breath has been a rich source of potential cancers biomarkers ${ }^{20,49,50}$. These biomarkers can be divided into three categories. The first category includes the small volatile compounds. These can be measured in the gas phase and, in the case of water-soluble compounds also in the breath condensate (e.g. ammonia and formic acid). The second category includes biomolecules of low-molecular weight (e.g. isoprostanes, polypeptides and nucleic acids). The third category is miscellaneous including many compounds such as lipid mediators, chemokines and cytokines. The second and third category are mainly present in the breath condensate. DNA from exhaled breath condensateEBC of healthy people has been used to identify mutations (e.g. TP53 gene mutations) that are associated with early neoplastic changes ${ }^{51}$. A recent study recognized several volatile organic compounds as breath gas biomarkers of thyroid cancer 49. Reported potential breath gas biomarkers for oral squamous cell carcinoma are alkanes, alkenes and aldehydes including undecane, dodecane, decanal, benzaldehyde, 3,7-dimethyl undecane, 4,5dimethyl nonane, 1-octene, and hexadecane when analyzed by solid-phase microextraction with 
gas chromatography-mass spectrometry ${ }^{52}$. By using linear discriminant analysis classification of these compounds, well-defined clusters for patients and controls have been revealed ${ }^{52}$. In addition, dimethyl disulfide, decamethylcyclopentasiloxane (D5) and p-xylene (PX) have been reported as gas phase biomarkers that decrease after surgery ${ }^{53}$. Ethanol, 2-propenenitrile and undecane have also been identified as exhaled gas biomarkers that could distinguish laryngeal and pharyngeal head and neck squamous cell carcinoma from benign tumors and from healthy subjects ${ }^{54}$.

\section{Exhaled breath analysis as a diagnostic tool in head and neck cancer}

Recent research has analyzed exhaled breath to aid in early detection of HNC $22,52,55$. An early attempt to analyze exhaled breath for diagnosis of HNC was conducted by Hakim et al. (2011) ${ }^{22}$ who used breath gas testing with an artificial nose based on gold nanoparticle sensors. They were able to recognize patients with HNC from healthy people and from patients with lung cancer ${ }^{22}$. The nanoparticle sensors did not provide identification of the biomarkers responsible for the sensor response. A few years later, Gruber et al. ${ }^{54}$ in their analysis of exhaled breath from patients with laryngeal and pharyngeal cancers found that ethanol, 2-propenenitrile and undecane can be used as potential biomarkers for these two cancers. Using artificially intelligent nanoarrays, Nakhleh et al. ${ }^{56}$ identified a set of many diseases including $\mathrm{HNC}$ from exhaled breath. In oral squamous cell carcinoma, a recent study used exhaled breath analysisEBA and found three compounds (benzaldehyde, 3,7-dimethylundecane, and butyl acetate) that have a relationship with pathological parameters of these cancers ${ }^{52}$. The methods used for EBA of HNC patients so far include gas chromatography-mass spectrometry ${ }^{51}$, various nanomaterial-based sensors ${ }^{22,53,55}$ and chemical $\underline{\text { ionization mass spectrometry }}^{54}$ 


\section{Exhaled breath analysis as a predictive tool to monitor the treatment outcome}

Assessment of treatment outcome is of great importance during follow-up for early identification of patients with residual or recurrent disease. Exhaled breath analysisEBA has been recently introduced as an effective tool for monitoring response to treatment in lung cancer ${ }^{57}$. In $\mathrm{HNC}$, Hakim et al 22 suggested that breath analysis using an artificial nose could be utilized as a test to follow-up after treatment of HNC especially for those cases at high-risk of developing second primary tumors. Moreover, breath analysis from cured patients who underwent resection of HNC was similar to breath analysis of healthy control, which potentially indicates a successful surgery 58. Interestingly, Hartwig et al. ${ }^{53}$ collected breath samples before and after surgical treatment of oral squamous cell carcinoma and compared the breath analysis for each case. They reported disappearance of cancer-associated volatile organic compounds in the breath after treatment ${ }^{53}$. However, using breath analysis in monitoring the treatment of HNC is still a new field of research that requires more scientific efforts. Also, the protocols would need to define further steps in the management of the patient population with positive findings in their breath samples.

\section{Conclusion and Future}

In recent years, exhaled breath analysisEBA has received increasing research interest in the early detection of many cancers. The currently available body of evidence refers to potential clinical use of exhaled breath in the early diagnosis of HNC. Such evidence requires further validation in large cohorts with comparison of different protocols that have been developed. That will allow standardization of the methods of breath sampling, including sample collection, storage, and analysis. It is noteworthy, that a recent review proposed a framework for conducting and reporting future studies investigating the role of VOCs in cancer diagnosis ${ }^{59}$. Translation of breath analysis 
from lab into clinic, after generalizability of the currently identified biomarkers, could be a step

toward early detection of HNC through screening of high-risk populations.

\section{References}

1. Bray F, Ferlay J, Soerjomataram I, Siegel RL, Torre LA, Jemal A. Global cancer statistics 2018: GLOBOCAN estimates of incidence and mortality worldwide for 36 cancers in 185 countries. $C A$ Cancer J Clin. 2018;68(6):394-424.

2. Gupta B, Johnson NW, Kumar N. Global Epidemiology of Head and Neck Cancers: A Continuing Challenge. Oncology. 2016;91(1):13-23.

3. Lechner M, Breeze CE, O'Mahony JF, Masterson L. Early detection of HPV-associated oropharyngeal cancer. Lancet. 2019;393(10186):2123.

4. Timbang MR, Sim MW, Bewley AF, Farwell DG, Mantravadi A, Moore MG. HPV-related oropharyngeal cancer: a review on burden of the disease and opportunities for prevention and early detection. Hum Vaccin Immunother. 2019;15(7-8):1920-1928.

5. Lee JY, Garcia-Murillas I, Cutts RJ, et al. Predicting response to radical (chemo)radiotherapy with circulating HPV DNA in locally advanced head and neck squamous carcinoma. $\mathrm{Br} J$ Cancer. 2017;117(6):876-883.

6. Rosenthal M, Huang B, Katabi N, et al. Detection of HPV related oropharyngeal cancer in oral rinse specimens. Oncotarget. 2017;8(65):109393-109401.

7. Hashim D, Genden E, Posner M, Hashibe M, Boffetta P. Head and neck cancer prevention: from primary prevention to impact of clinicians on reducing burden. Ann Oncol. 2019;30(5):744-756.

8. Oakley-Girvan I, Davis SW. Breath based volatile organic compounds in the detection of breast, lung, and colorectal cancers: A systematic review. Cancer Biomark. 2017;21(1):29-39.

9. Altomare DF, Di Lena M, Porcelli F, et al. Exhaled volatile organic compounds identify patients with colorectal cancer. Br J Surg. 2013;100(1):144-150.

10. Schmekel B, Winquist F, Vikstrom A. Analysis of breath samples for lung cancer survival. Anal Chim Acta. 2014;840:82-86.

11. Lavra L, Catini A, Ulivieri A, et al. Investigation of VOCs associated with different characteristics of breast cancer cells. Sci Rep. 2015;5:13246.

12. Qin T, Liu H, Song Q, et al. The screening of volatile markers for hepatocellular carcinoma. Cancer Epidemiol Biomarkers Prev. 2010;19(9):2247-2253.

13. Waltman CG, Marcelissen TAT, van Roermund JGH. Exhaled-breath Testing for Prostate Cancer Based on Volatile Organic Compound Profiling Using an Electronic Nose Device (Aeonose): A Preliminary Report. Eur Urol Focus. 2018.

14. Adam ME, Fehervari M, Boshier PR, et al. Mass-Spectrometry Analysis of Mixed-Breath, IsolatedBronchial-Breath, and Gastric-Endoluminal-Air Volatile Fatty Acids in Esophagogastric Cancer. Anal Chem. 2019;91(5):3740-3746.

15. Amann A, Miekisch W, Schubert J, et al. Analysis of exhaled breath for disease detection. Annu Rev Anal Chem (Palo Alto Calif). 2014;7:455-482.

16. Henderson B, Khodabakhsh A, Metsala M, et al. Laser spectroscopy for breath analysis: towards clinical implementation. Appl Phys B. 2018;124(8):161.

17. Di Natale C, Paolesse R, Martinelli E, Capuano R. Solid-state gas sensors for breath analysis: a review. Anal Chim Acta. 2014;824:1-17. 
18. Horvath I, Hunt J, Barnes PJ, et al. Exhaled breath condensate: methodological recommendations and unresolved questions. Eur Respir J. 2005;26(3):523-548.

19. Carpagnano GE, Koutelou A, Natalicchio MI, et al. HPV in exhaled breath condensate of lung cancer patients. Br J Cancer. 2011;105(8):1183-1190.

20. Li J, Peng Y, Liu Y, et al. Investigation of potential breath biomarkers for the early diagnosis of breast cancer using gas chromatography-mass spectrometry. Clin Chim Acta. 2014;436:59-67.

21. Lawal O, Ahmed WM, Nijsen TME, Goodacre R, Fowler SJ. Exhaled breath analysis: a review of 'breath-taking' methods for off-line analysis. Metabolomics. 2017;13(10):110.

22. Hakim M, Billan S, Tisch U, et al. Diagnosis of head-and-neck cancer from exhaled breath. $\mathrm{Br} J$ Cancer. 2011;104(10):1649-1655.

23. Modak AS. Single time point diagnostic breath tests: a review. J Breath Res. 2010;4(1):017002.

24. de Lacy Costello B, Amann A, Al-Kateb H, et al. A review of the volatiles from the healthy human body. J Breath Res. 2014;8(1):014001.

25. Herbig J, Beauchamp J. Towards standardization in the analysis of breath gas volatiles. $J$ Breath Res. 2014;8(3):037101.

26. Czebe K, Barta I, Antus B, Valyon M, Horvath I, Kullmann T. Influence of condensing equipment and temperature on exhaled breath condensate $\mathrm{pH}$, total protein and leukotriene concentrations. Respir Med. 2008;102(5):720-725.

27. Vyas A, Zhang Q, Gunaratne S, et al. The effect of temperature on exhaled breath condensate collection. J Breath Res. 2012;6(3):036002.

28. Koskela HO, Purokivi MK, Nieminen RM, Moilanen E. Asthmatic cough and airway oxidative stress. Respir Physiol Neurobiol. 2012;181(3):346-350.

29. Mutti A, Corradi M, Goldoni M, Vettori MV, Bernard A, Apostoli P. Exhaled metallic elements and serum pneumoproteins in asymptomatic smokers and patients with COPD or asthma. Chest. 2006;129(5):1288-1297.

30. Soyer OU, Dizdar EA, Keskin O, Lilly C, Kalayci O. Comparison of two methods for exhaled breath condensate collection. Allergy. 2006;61(8):1016-1018.

31. Moeller A, Franklin P, Hall GL, Horak F, Jr., Wildhaber JH, Stick SM. Measuring exhaled breath condensates in infants. Pediatr Pulmonol. 2006;41(2):184-187.

32. Vogelberg C, Wurfel C, Knoetzsch A, Kahlert A, Range U, Leupold W. Exhaled breath condensate $\mathrm{pH}$ in infants and children with acute and recurrent wheezy bronchitis. Pediatr Pulmonol. 2007;42(12):1166-1172.

33. Rosias PP, Robroeks CM, van de Kant KD, et al. Feasibility of a new method to collect exhaled breath condensate in pre-school children. Pediatr Allergy Immunol. 2010;21(1 Pt 2):e235-244.

34. Carter SR, Davis CS, Kovacs EJ. Exhaled breath condensate collection in the mechanically ventilated patient. Respir Med. 2012;106(5):601-613.

35. Dweik RA, Boggs PB, Erzurum SC, et al. An official ATS clinical practice guideline: interpretation of exhaled nitric oxide levels (FENO) for clinical applications. Am J Respir Crit Care Med. 2011;184(5):602-615.

36. Vaughan J, Ngamtrakulpanit L, Pajewski TN, et al. Exhaled breath condensate $\mathrm{pH}$ is a robust and reproducible assay of airway acidity. Eur Respir J. 2003;22(6):889-894.

37. Chapman EA, Thomas PS, Yates DH. Breath analysis in asbestos-related disorders: a review of the literature and potential future applications. J Breath Res. 2010;4(3):034001.

38. Liu J, Conrad DH, Chow S, Tran VH, Yates DH, Thomas PS. Collection devices influence the constituents of exhaled breath condensate. Eur Respir J. 2007;30(4):807-808.

39. Borrill ZL, Roy K, Singh D. Exhaled breath condensate biomarkers in COPD. Eur Respir J. 2008;32(2):472-486.

40. Huttmann EM, Greulich T, Hattesohl A, et al. Comparison of two devices and two breathing patterns for exhaled breath condensate sampling. PLoS One. 2011;6(11):e27467.

41. Mochalski P, King J, Unterkofler K, Amann A. Stability of selected volatile breath constituents in Tedlar, Kynar and Flexfilm sampling bags. Analyst. 2013;138(5):1405-1418. 
42. Kang S, Paul Thomas CL. How long may a breath sample be stored for at -80 degrees C? A study of the stability of volatile organic compounds trapped onto a mixed Tenax:Carbograph trap adsorbent bed from exhaled breath. J Breath Res. 2016;10(2):026011.

43. Youssef O, Sarhadi VK, Armengol G, Piirila P, Knuuttila A, Knuutila S. Exhaled breath condensate as a source of biomarkers for lung carcinomas. A focus on genetic and epigenetic markers-A minireview. Genes Chromosomes Cancer. 2016;55(12):905-914.

44. Zetterquist W, Marteus H, Kalm-Stephens P, et al. Oral bacteria--the missing link to ambiguous findings of exhaled nitrogen oxides in cystic fibrosis. Respir Med. 2009;103(2):187-193.

45. Effros RM, Hoagland KW, Bosbous M, et al. Dilution of respiratory solutes in exhaled condensates. Am J Respir Crit Care Med. 2002;165(5):663-669.

46. Jackson AS, Sandrini A, Campbell C, Chow S, Thomas PS, Yates DH. Comparison of biomarkers in exhaled breath condensate and bronchoalveolar lavage. Am J Respir Crit Care Med. 2007; 175(3):222-227.

47. Chen W, Metsala M, Vaittinen O, Halonen L. The origin of mouth-exhaled ammonia. J Breath Res. 2014;8(3):036003.

48. Chen W, Metsala M, Vaittinen O, Halonen L. Hydrogen cyanide in the headspace of oral fluid and in mouth-exhaled breath. J Breath Res. 2014;8(2):027108.

49. Guo L, Wang C, Chi C, et al. Exhaled breath volatile biomarker analysis for thyroid cancer. Transl Res. 2015;166(2):188-195.

50. Youssef O, Knuuttila A, Piirila P, Bohling T, Sarhadi V, Knuutila S. Hotspot Mutations Detectable by Next-generation Sequencing in Exhaled Breath Condensates from Patients with Lung Cancer. Anticancer Res. 2018;38(10):5627-5634.

51. Youssef O, Knuuttila A, Piirila P, Bohling T, Sarhadi V, Knuutila S. Presence of cancer-associated mutations in exhaled breath condensates of healthy individuals by next generation sequencing. Oncotarget. 2017;8(11):18166-18176.

52. Bouza M, Gonzalez-Soto J, Pereiro R, de Vicente JC, Sanz-Medel A. Exhaled breath and oral cavity VOCs as potential biomarkers in oral cancer patients. J Breath Res. 2017;11(1):016015.

53. Hartwig S, Raguse JD, Pfitzner D, Preissner R, Paris S, Preissner S. Volatile Organic Compounds in the Breath of Oral Squamous Cell Carcinoma Patients: A Pilot Study. Otolaryngol Head Neck Surg. 2017;157(6):981-987.

54. Gruber M, Tisch U, Jeries R, et al. Analysis of exhaled breath for diagnosing head and neck squamous cell carcinoma: a feasibility study. Br J Cancer. 2014;111(4):790-798.

55. Chandran D, Ooi EH, Watson DI, Kholmurodova F, Jaenisch S, Yazbeck R. The Use of Selected Ion Flow Tube-Mass Spectrometry Technology to Identify Breath Volatile Organic Compounds for the Detection of Head and Neck Squamous Cell Carcinoma: A Pilot Study. Medicina (Kaunas). 2019;55(6).

56. Nakhleh MK, Amal H, Jeries R, et al. Diagnosis and Classification of 17 Diseases from 1404 Subjects via Pattern Analysis of Exhaled Molecules. ACS Nano. 2017;11(1):112-125.

57. Nardi-Agmon I, Abud-Hawa M, Liran O, et al. Exhaled Breath Analysis for Monitoring Response to Treatment in Advanced Lung Cancer. J Thorac Oncol. 2016;11(6):827-837.

58. Lang HP, Loizeau F, Hiou-Feige A, et al. Piezoresistive Membrane Surface Stress Sensors for Characterization of Breath Samples of Head and Neck Cancer Patients. Sensors (Basel). 2016;16(7).

59. Hanna GB, Boshier PR, Markar SR, Romano A. Accuracy and Methodologic Challenges of Volatile Organic Compound-Based Exhaled Breath Tests for Cancer Diagnosis: A Systematic Review and Meta-analysis. JAMA Oncol. 2019;5(1):e182815. 